\title{
Literatur
}

1. Treiber, L. und G. W. Oertel, diese Z., 5, 83 (1967). - 2. Bethge, H., W. Winkelmann und H. ZimmermanN, Klin. Wschr. 43, 1274 (1965). - 3. de Paoli, J. C., E. Nishizawa und K. B. Eik-Nes, J. Clin. Endocr., Springfield 23, 81 (1963). - 4. LrsboA, B. P., Acta endocr. K'hvn. 43, 47 (1963). - 5. Hamman, B. L. und M. M. Martin, J. Clin. Endocr., Springfield 24, 1195 (1964). 6. Oertel, G. W. und K. Groot, Clin. chim. Acta (Amsterdam) 11, 512 (1965). - 7. Conrad, S., V. B. Mahesh und W. HerrmanN, J. clin. Invest. 40, 947 (1961). - 8. SANDbERG, D. H., N. Ahmad, M. Zachman und W. W. Cleveland, Steroids 6,777 (1965). - 9. Oertel, G. W. und E. Kaiser, Clin. chim. Acta
(Amsterdam) 7, 221 (1962). - 10. RrNDr, W., Acta endocr. K'hvn. 50, 403 (1965). - 11. Sommervilie, I. F. und G. N. Deshrande, J. Clin. Endocr., Springfield 18, 1223 (1958). - 12. Treiber, L., W. Rindt und G. W. Oertel, J. Chromatogr. (Amsterdam), im Druck. - 13. Bondy, P. K., G. I. CohN und P. G. Gregory, Medicine, Baltimore 44, 249 (1965). - 14. ZimmermanN, W., Hoppe-Seyler's Z. physiol. Chem. 233, 251 (1935). - 15. Short, R. V. und I. Levetr, J. Endocr. 25, 239 (1962). - 16. StupNickr, R. und E. Stupnicka, J. Chromatogr. (Amstè̀dam) 9, 235 (1962). - 17. Reich, H., K. F. Crane und S. J. Sanfirrppo, J. biol. Chemistry 198, 713 (1952); J. org. Chemistry 18, 822 (1953).

Dozent Dr. G. W. Oertel

65 Mainz, Langenbeckstraße 1

\section{Dünnschichtchromatographie von Aminosäuren und Aminen im Stuhl}

\author{
Von F. TANCREDi ${ }^{1}$ ) und H.-Ch. CuRTius \\ Aus dem Chemischen Laboratorium der Universitäts-Kinderklinik Züricb (Direktor: Prof. Dr. A. Prader)
}

(Fingegangen am 13. Juli 1966)

Es wird eine dünnschichtchromatographische Methode zur Bestimmung der Aminosäuren und Amine im Stuhl in Form ihrer DNPDerivate beschrieben. Die Methode gestattet eine einfache Abtrennung der Störsubstanzen und eine getrennte Bestimmung von Aminosäuren und Aminen. Bei den untersuchten Normalfällen war das Spektrum an Aminosäuren und Aminen relativ einheitlich. Die Hauptmenge der Stuhlaminosäuren besteht aus ätherlöslichen; im säurelöslichen Extrakt fanden wir bei den von uns untersuchten Stühlen praktisch nur Arginin, Taurin, Cysteinsäure und ausnahmsweise Histidin. Die Hauptmenge der Stuhlamine besteht aus Putrescin und Cadaverin.

A thin layer chromatographic method is described for the determination of feacal amino acids and amines as their DNP-derivatives. There is a simple separation from interfering substances, followed by the separate measurement of amino acids and amines. In normal cases, the pattern of amino acids and amines was relatively uniform. The majority of the faecal amino acids are ether-soluble; in the acid-soluble extract of the faeces studied, we found practically only arginine, taurine, cysteic acid, while histidine was an exception. Putrescine and cadaverine are the chicf faecal amines.

Über die im Stuhl vorhandenen Aminosäuren und Amine liegen nur wenige Arbeiten vor $(1,2,3)$. Grundsätzlich können für deren Untersuchung die gleichen Methoden in Betracht gezogen werden wie bei anderem biologischen Material, z. B. Urin $(4,5,6)$. Der Stuhl ist ein unhomogenes Material, das große Mengen von verschiedenen Substanzen enthält, wie Eiweiße, Fette, Kohlenhydrate, Pigmente, Cellulose, anorganische Salze usw. Diese Stoffe müssen vor der Chromatographie abgetrennt werden. $\mathrm{Zu}$ diesem Zweck eignet sich die Dünnschichtchromatographie der DNP-Aminosäuren vorzüglich. Bei diesem Verfahren werden die Aminosäuren und Amine in die entsprechenden wasserunlöslichen DNP-Derivate überfühtt und anschließend aus dem wäßrigen Milieu extrahiert. Nach Abtrennung von den festen Bestandteilen und Extraktion sollte es auch beim Stuhl möglich sein, die Aminosäuren, Peptide und Amine in ihrer dinitrophenylierten Form zu erfassen.

Für die Dinitrophenylierung und dünnschichtchromatographische Auftrennung der äther- und säurelöslichen DNP-Derivate haben WALZ und Mitarbeiter (8) sowie für die säurelöslichen auch BürgI und Mitarbeiter (9) Arbeitsvorschriften bekanntgegeben. Diese Methoden wurden der vorliegenden Arbeit teilweise zugrunde gelegt. Die Amine wurden im Dioxan-Wasser-Gemisch

1) Stipendiat der Roche-Studienstiftung. nach MCINTIRE und Mitarbeitern (10) dinitrophenyliert und anschließend in einem Fließmittelsystem nach Pataki (11) chromatographiert.

\section{Methodik}

Geräte

Ausrüstung zur Dünnschichtchromatographie der Fa. Desaga, Heidelberg (Chromatographieplatten $20 \times 20 \mathrm{~cm}$ ).

Schüttelwasserbad (Arbeitstemperatur $60^{\circ}$ ).

Rotationsverdampfer der Fa. Büchi, Flawil

Trockenschrank (Arbeitstemperatur $110^{\circ}$ ).

Homogenisator der Fa. Silverson, London.

\section{Chemikalien}

2,4-Dinitrofluorbenzol, Fa. Fluka, Art.-Nr. A 53567; Putrescin, Fa. Fluka, Art.-Nr. A 52777; Cadaverin, Fa. Fluka, Art.-Nr. A 52820;Aceton, Fa. Merck, Art.-Nr. 14; Ammoniak 2,5-proz., Fa. Merck, Art.-Nr. 5432; Athanol, Fa. Merck, Art.-Nr. 90972; Äthylacetat, Fa. Fluka, Art.-Nr. A 53848; Benzylalkohol, Fa. Merck, Art.-Nr. 981; Benzzol, Fa. Merck, Art.-Nr. 91783; nButanol, Fa. Merck, Art.-Nr. 988; 2-Chloräthanol, Fa. Fluka, Art.-Nr. A 52005; Chloroform, Fa. Fluka, Art.-Nr. A 52219; Dioxan, Fa. Fluka, Art.-Nr. A 53609; Eisessig, Fa. Merck, Art.Nr. 90058; Methanol, Fa. Merck, Art.-Nr. 6006; Natriumsulfat wasserfrei, Fa. Fluka, Art.-Nr. A 56083; Natriumhydrogencarbonat, Fa. Merck, Art.-Nr. 6323; Natriumhydroxyd, Fa. Fluka, Art.-Nr. A 56051; Pyridin, Fa. Merck, Art.-Nr. 7461 ; Toluol, Fa. Merck, Art.-Nr. 98323; Tetrachloräthan, Fa. Fluka, Art.-Nr. 57 512; Salzsäure, Fa. Merck, Art.-Nr. 312; Kongopapier-Phenolphtbaleinpapier; Kieselgel G nach Stahl, Fa. Merck, Art.-Nr. 7731. 


\section{Reagenzien}

Natronlauge $5 \mathrm{~N}$

Salzsäure $6 \mathrm{~N}$

Natriumhydrogencarbonat $0,1 \mathrm{M}$

Karbonatpuffer $\mathrm{pH} 8,8: 8,4 \mathrm{~g} \mathrm{NaHCO}_{3}$ in abgekochtem aqua dest. auflösen (nicht erwärmen!) mit Natronlauge $5 \mathrm{~N}$ auf $\mathrm{pH} 8,8$ einstellen und mit $\mathrm{H}_{2} \mathrm{O}$ auf $100 \mathrm{~m} /$ auffüllen.

DNFB-Lösung: 10-proz. Lösung in abs. Alkohol (jeweils frisch bereiten)

Natronlauge $0,2 \mathrm{~N}$ in 60 -proz. Dioxan

Essigsäureäthylester/Butanol 1:1 (v:v)

Zubereitung der Sorptionsschicht: Die Herstellung der DC-Platten erfolgte in der üblichen Weise mit Kieselgel G nach Stahl. Die Platten wurden aber luftgetrocknet und offen aufbewahrt (7). Testsubstanzen:

Dic DNP-Aminosäuren wurden von der Fa. Serva AG, Heidelberg, Art.-Nr. 39040 bezogen.

\section{Fließmittel ${ }^{1}$ )}

1: Toluol/2-Chloräthanol/Pyridin/Ammoniak 25-proz. 50:35:15:7 $(\mathrm{v} / \mathrm{v} / \mathrm{v} / \mathrm{v})$

2: Chloroform/Benzylalkohol/Eisessig 70:30:3 ( $/ / \mathrm{v} / \mathrm{v})$

3: Phenol/Wasser/Ammoniak 17-proz. 80:20:2 (g/v/v)

4: 2-Chloräthanol/Toluol/Pyridin/Ammoniak 20-proz.50:35:15:10 $(\mathrm{v} / \mathrm{v} / \mathrm{v} / \mathrm{v})$

5: Chloroform/Methanol/Eisessig 100:2:1 ( $/ \mathrm{v} / \mathrm{v})$

6: Benzol/Äthylacetat $1: 1(\mathrm{v} / \mathrm{v})$

7: Pyridin

8: n-Butylalkohol mit 25-proz. Ammoniak bei Zimmertemperatur gesättigt.

Verwendete Abkürzungen

Alanin (Ala)

$\beta$-Alanin ( $\beta$-Ala)

$\alpha$-Amino-Adipinsäure (Aad)

$\gamma$-Aminobuttersäure ( $\gamma$-Abut)

$\beta$-Aminoisobuttersäure $(\beta-A i B)$

Arginin (Arg)

Asparagin $\left(\mathrm{Asp}\left(\mathrm{NH}_{2}\right)\right)$

Asparaginsäure (Asp)

Cadaverin (Cad)

Citrullin (Cit)

Cysteinsäure $\left(\mathrm{CysSO}_{3} \mathrm{H}\right)$

Cystin (Cys)

2,4-Dinitroanilin (DNP-NH ${ }_{2}$ )

2,4-Dinitrophenol (DNP-OH)

Glutamin $\left(\mathrm{Glu}\left(\mathrm{NH}_{2}\right)\right)$

Glutaminsäure (Glu)

Glycin (Gly).

Histamin (Hista)

Histidin (His)

Homoarginin (H'Arg)

Dinitrofluorbenzol $=$ DNFB

Arbeitsvorschrift

\section{Herstellung der DNP-Derivate aus synthetischen Aminen}

Putrescin, Cadaverin, Tyramin, Phenyläthylamin und Histamin werden nach der Methode von McINTIRE und Mitarbeitern (10) dinitrophenyliert: $10 \mathrm{ml}$ einer 0,01-proz. wäßr. Lösung des jeweiligen Amins werden in einem Erlenmeyerkolben mit $1 \mathrm{ml}$ 10-proz DNFB und $2 \mathrm{ml} 0,1 \mathrm{M} \mathrm{NaHCO}$-Lösung versetzt. Das Gemisch wird während $20 \mathrm{Min}$. in einem Wasserbad von $60^{\circ}$ geșchüttelt; anschließend werden $10 \mathrm{ml} 0,2 \mathrm{~N} \mathrm{NaOH}$ in 60-proz. Dioxan zugefügt und während einer Stunde bei $60^{\circ}$ weitergeschüttelt. Das auf Zimmertemperatur abgeküblte Reaktionsgemisch wird mit $10 \mathrm{ml}$ aqua dest. versetzt und viermal mit $10 \mathrm{ml}$ Tetrachloräthan extrahiert. Die die DNP-Amine enthaltenden vereinigten Extrakte werden zur Trockene eingedampft. Zur Herstellung einer Gebrauchslösung wird der Rückstand in $1 \mathrm{ml}$ Tetrachloräthan aufgenommen.

\section{Extraktion des Stubls}

Man versetzt $10 \mathrm{~g}$ frischen Stuhl mit $100 \mathrm{ml}$ aqua dest. und homogenisiert die Mischung während 10 Min. Das Homogenat wird zentrifugiert und der Uberstand abdekantiert. Das Zentrifugat wird mit $100 \mathrm{~m} /$ Wasser nachgẹ wașchen. Die vereinigten wäßr. Extrakte

1) Fließmittel 1, 2, 7 und 8 nach $W_{A L Z}$ und Mitarbeitern; Fließmittel 5 nach PATAKI und Fließmittel 3 und 4 nach Bürgi und Mitarbeitern. werden durch Filterpapier filtriert und, wenn nicht sofort weiterverarbeitct, bei $-20^{\circ}$ aufbewahrt. Dicse Lösung wird dinitrophenylicrt.

\section{Dinitrophenylierung der Stubl-Aminosäuren}

a) Ätherlösliche Aminosäuren (nach $(7,8)$ )

$20 \mathrm{ml}$ Stuhlextrakt werden mit $5 \mathrm{~N} \mathrm{NaOH}$ phenolphthaleinalkalisch gemacht und mit $5 \mathrm{ml}$ Karbonatpuffer und $2 \mathrm{~m} l$ frisch bereiteter alkoholischer DNFB-Lösung versetzt. Die Mischung wird während einer Stunde in einem geschlossenen Erlenmeyerkolben im Wasserbad von $40^{\circ}$ geschüttelt. Das auf Zimmertemperatur abgekühlte Reaktionsgemisch wird dreimal mit etwa $10 \mathrm{~m} l$ Äther extrahiert. Die Ätherextrakte werden verworfen, da sie außer dem überschüssigen DNFB im wesentlichen nur 2,4-Dinitrophenol enthalten $\left.{ }^{2}\right)$. Die wäßr. Lösung wird tropfenweise $\left(\mathrm{CO}_{2}\right.$ Entwicklung!) unter Umrühren mit $6 \mathrm{~N} \mathrm{HCl}$ bis zur deutlichen Blaufärbung von Kongopapier angesäuert. Man extrahiert sie sechsmal mit je $10 \mathrm{~m} /$ Äther. Die vereinigten Ätherextrakte, welche die ätherlöslichen Aminosäuren enthalten, werden über ausgeglühtem $\mathrm{Na}_{2} \mathrm{SO}_{4}$ getrocknet, filtriert und eingedampft (Extrakt 1). Wird der Extrakt nicht sofort chromatographiert, muß er im Dunkeln im Eisschrank $\left(0-4^{\circ}\right)$ aufbewahrt werden.

b) Säurelösliche Aminosäuren (nach $(7,8,9)$ )

Nach der Extraktion der ätherlöslichen Aminosäuren wird die wäßr. Phase sechsmal mit je $10 \mathrm{~m} l$ eines aus gleichen Volumenteilen bereitcten Gemisches von Essigester und n-Butanol extrahiert. Die vereinigten Extrakte werden über ausgeglühtem $\mathrm{Na}_{2} \mathrm{SO}_{4}$ getrocknet und durch Watte filtriert. Man wäscht $\mathrm{Na}_{2} \mathrm{SO}_{4}$ und Filterwatte mit etwas Essigester/Butanol aus und dampft das Filtrat zur Trockene ein. Der Rückstand wird nochmals in $3 \mathrm{~m} l$ Wasser gelöst und durch Watte filtriert. Nach Waschen der Watte mit Wasser, dampft man das Filtrat zur Trockene ein (Extrakt 2). Der Extrakt enthält die säurelöslichen Aminosäuren und wird, wenn nicht sofort chromatographiert im Dunkeln bei $4^{\circ}$ aufbewahrt.

Dinitrophenylierung der Stubl-Amine (nach (10))

$20 \mathrm{~m} l$ Stuhlextrakt werden in einem Erlenmeyerkolben mit $2,5 \mathrm{~m} l$ 10-proz. DNFB und $5 \mathrm{~m} / 0,1 \mathrm{M} \mathrm{NaHCO}_{3}$-Lösung versetzt. Das Gemisch wird in einem Wasserbad $\left(60^{\circ}\right)$ während 20 Min. geschüttelt; dann fügt man $30 \mathrm{~m} l 0,2 \mathrm{~N} \mathrm{NaOH}$ in Dioxan zu und schüttelt noch eine weitere Stunde bei $60^{\circ}$. Das auf Zimmertemperatur abgeküblte Gemisch wird mit $10 \mathrm{ml} \mathrm{H}_{2} \mathrm{O}$ versetzt und viermal mit $10 \mathrm{~m} l$ Tetrachloräthan extrahiert. Die vereinigten Extrakte werden über ausgeglühtem $\mathrm{Na}_{2} \mathrm{SO}_{4}$ getrocknet und im Vakuum eingedampft (Extrakt 3). Wenn man nicht sofort chromatographiert, wird der Rückstand im Dunkeln bei $4^{\circ}$ aufbewahrt.

\section{Dïnnscbichtchromatographie der DNP-Aminosäuren}

Für Einzelheiten der Technik weisen wir auf das neue Buch von G. Patakr (7) hin. Dort können alle Angaben über die Zubereitung der Schicht, das Auftragen der Substanzen, die Kammersättigung sowie die ein- und zweidimensionale Technik gefunden werden.

a) Ätherlösliche DNP-Aminosäuren (nach (8)):

Extrakt 1 wird in $2 \mathrm{ml}$ Aceton aufgenommen. Von dieser Lösung werden zwei verschiedene Konzentrationen, nämlich 10 und $20 \mu l$ auf die Dünnschicht-Platte aufgetragen. Man entwickelt diese Platte zuerst im Fließmittel 1; nach Zwischentrocknung (10 Min. Luftstrom bis zum Weißwerden der Schicht) wird die Entwicklung im gleichen Fließmittel in der gleichen Richtung wiederholt. Vor dem Chromatographieren in der zweiten Dimension werden die Platten gut getrocknet (10 Min. Luftstrom, 10 Min. Trockenschrank $60^{\circ}, 15$ Min. Luftstrom) und im Fließmittel 2 entwickelt.

b) Säurelösliche DNP-Aminosäuren (nach (9)):

Extrakt 2 wird in $2 \mathrm{~m} l$ Essigester/Butanol aufgenommen und zwei verschiedene Konzentrationen, nämlich 40 und $80 \mu l$, auf zwei Platten aufgetragen. Man entwickelt zunächst im Fließmittel 3 und trocknet über Nacht bei Zimmertemperatur. Vor der Entwicklung in der zweiten Dimension werden die Platten 10 Min. lang in den

2) Die Amine Putrescin, Cadaverin, Tyramin, Histamin, Phenyläthylamin reagieren niclbt mit DNFB unter diesen Bedingungen. 


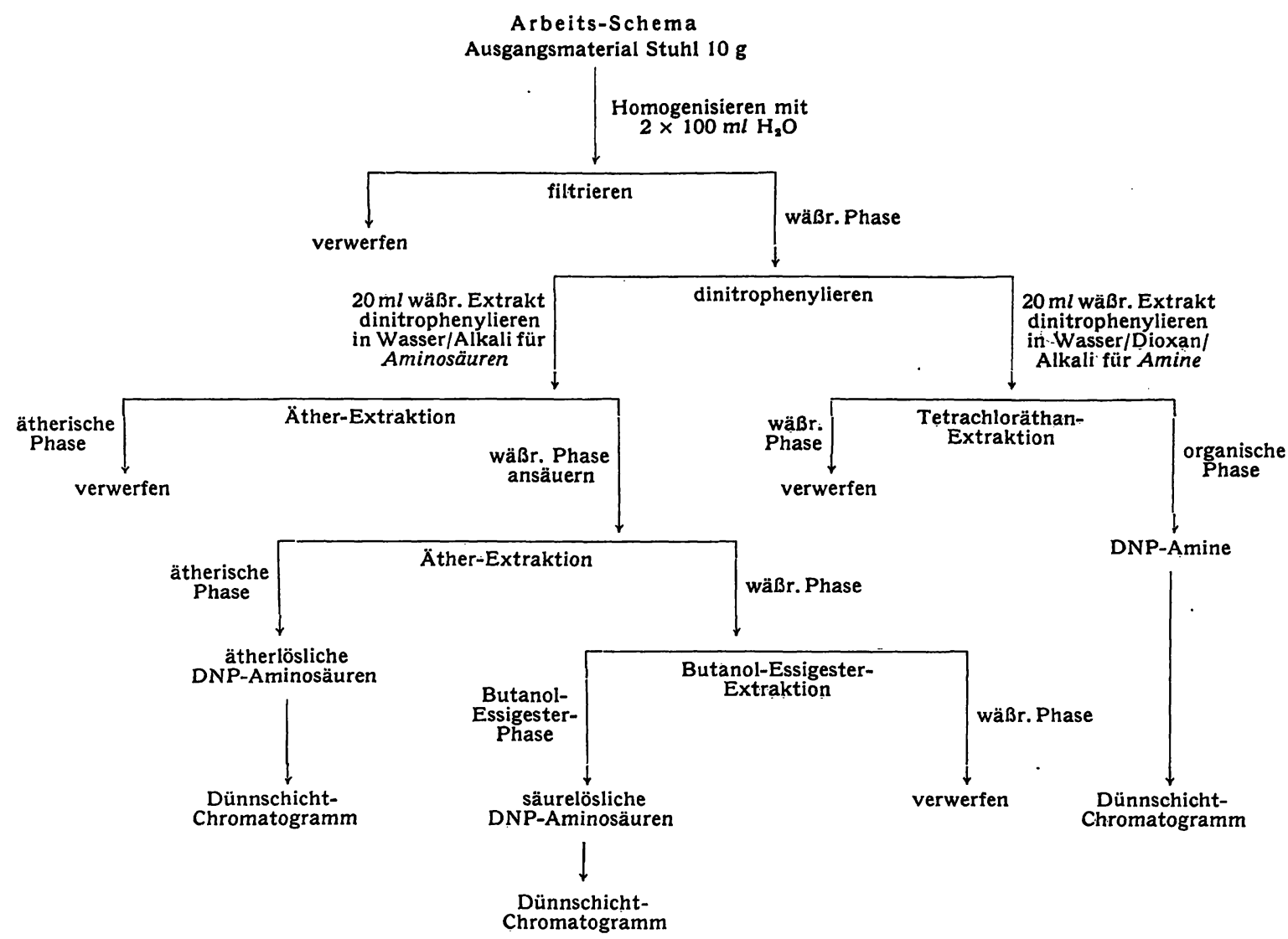

Trockenschrank $\left(60^{\circ}\right)$ gestellt. Anschließend wird in der zweiten Dimension im Fließmittel 4 entwickelt (nach (8) entwickelt man zweimal im Fließmittel 7 und einmal im Fließmittel 8).

\section{Dünnschichtchromatographie der DNP-Amine}

Der Extrakt 3 wird in $2 \mathrm{ml}$ Tetrachloräthan aufgenommen und auf zwei Platten in zwei verschiedenen Konzentrationen, nämlich 10 und $20 \mu l$ aufgetragen. Die Chromatographie wird zweidimensional durchgeführt: Erste Dimension im Fließmittel 5, dann nach Zwischentrocknung (10 Min. Luftstrom, $10 \mathrm{Min}$. Trockenschrank $60^{\circ}, 10 \mathrm{Min}$. Luftstrom), zweite Dimension im Fließmittel 6.

\section{Interpretation der Chromatogramme}

Das Identifizieren der DNP-Verbindungen auf den Chromatogrammen bereitet in der Regel keine Schwierigkeiten und kann anhand eines Fleckenmusters, das man durch Chromatographie einer Standardmischung erhält, sehr vereinfacht werden. Die unbekannten Flecken stören im allgemeinen nicht.

In Abbildung 1 ist das Fleckenmuster von ätherlöslichen DNPAminosäuren, in Abbildung 2 von säurelöslichen DNP-Aminosäuren und in Abbildung 3 von DNP-Aminen dargestellt. Das Fleckenmuster der Amine ist unvollständig und zeigt lediglich 5 Amine, die wir untersucht haben.

\section{Dokumentation der Resultate}

Die gelben DNP-Verbindungen lassen sich am besten auf ein Transparent-Zeichenpapier kopieren, wenn die Platten mit weißem Licht von unten beleuchtet werden. Für die Normallicht- und die UV-Photographie weisen wir auf das Buch von G. Patakr (7) hin. (Abb. 4).

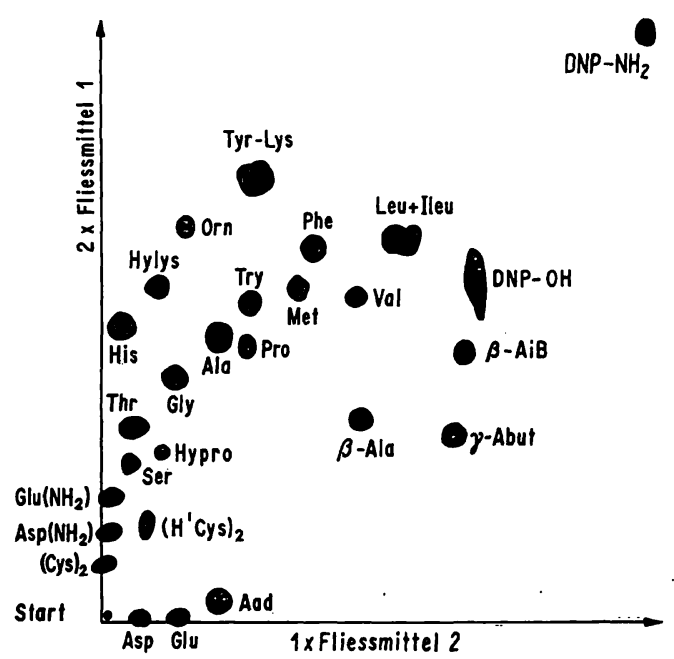

Abb. 1

Fleckenmuster für die ätberlöslichen DNP-Aminosäuren

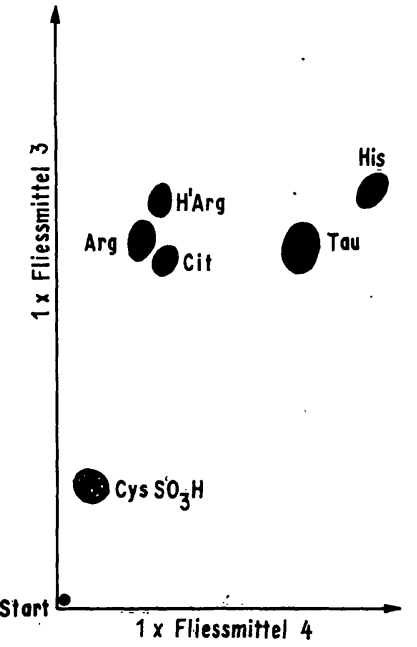

Abb. 2

Fleckenmuster für die säurelöslichen DNP-Aminosäuren

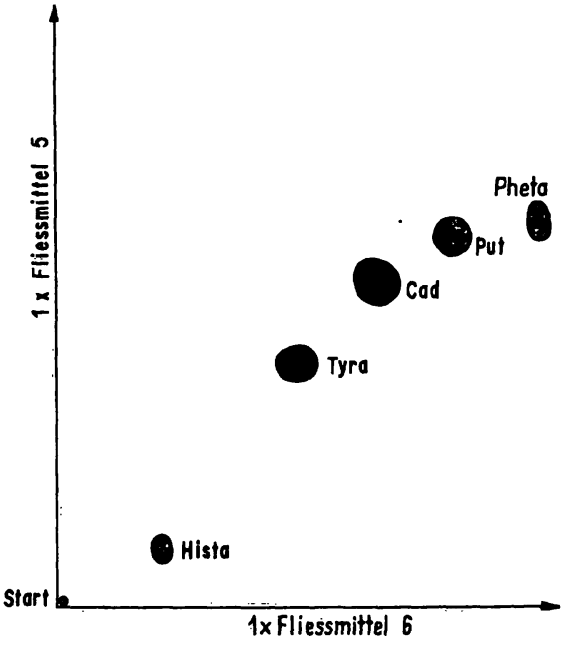

Abb. 3

Fleckenmuster für die DNP-Amine 


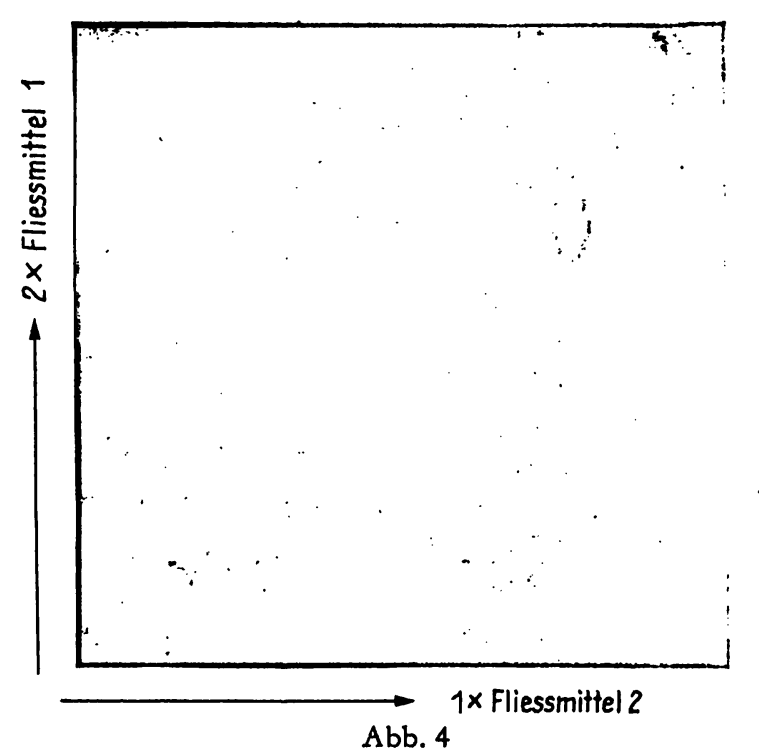

Normallicht-Photographic: ätherlösliche DNPAminosäuren cines Stuhls

\section{Ergebnisse}

Wir haben den Stuhl von 8 Kindern im Alter zwischen 8 Monaten und 3 Jahren untersucht. Diese Patienten waren in unserer Klinik wegen akuter Erkrankungen hospitalisiert und befanden sich in der Erholungszeit. Keines dieser Kinder hatte eine akute oder chronische Darmstörung - alle wurden mit der normalen Spitalkost ernährt. In der Regel nahmen wir eine Portion des Morgenstuhls, manchmal wurden aber auch zwei oder drei Stühle desselben Kindes von verschiedenen Tagen untersucht. Beim Vergleich von mehreren Stühlen von verschiedenen Kindern und von Stühlen vom gleichen Kind haben wir gesehen, daß das Bild der Aminosäuren überraschenderweise relativ konstant bleibt.

Um einen Extraktionsverlust auszuschließen, haben wir die Stühle auch im sauren ( $\mathrm{pH} 2-3$ ) und im alkalischen Milieu ( $\mathrm{pH} 9-10$ ) homogenisiert. Die Extraktion ist im alkalischen Milieu besser als im sauren, aber keineswegs so gut wie im neutralen Milieu. Die Wiederauffindungsrate dem Stuhl zugesetzter Aminosäuren ist bei der
Extraktion im sauren Milieu sehr niedrig; im alkalischen Milieu etwa $70 \%$ und bei der Extraktion im neutralen Bereich fast quantitativ.

In den Abbildungen 5, 6 und 7 werden einige unserer Aminosäuren-Chromatogramme gezeigt.

Die Hauptmenge der Stuhl-Aminosäuren besteht aus ätherlöslichen Aminosäuren. Im säurelöslichen Extrakt fanden wir bei unseren Stühlen und unseren chromatographischen Konzentrationen praktisch nur Arginin, Taurin, Cysteinsäure und ausnahmsweise Histidin. Im Chromatogramm der ätherlöslichen Aminosäuren Abb. 5) erscheinen DNP-Lysin und DNP-Tyrosin nicht getrennt. Auch die Trennung von DNP-Leucin und DNP-Isoleucin ist meistens ungenügend. Zur Trennung dieser Verbindung vgl. (7).

In Abbildung 7 wird ein Chromatogramm der Stuhlamine gezeigt: Die Hauptmenge besteht aus Putrescin und Cadaverin. Die unbekannten Flecken sind anscheinend auch Amine, wurden aber nicht identifiziert.

\section{Diskussion}

Es liegen nur wenige Arbeiten über den Aminosäureund Aminnachweis im Stuhl vor $(1,2,7)$. Die bisherigen Methoden erfordern teilweise umfangreiche Vorreinigungsarbeiten zur Entfernung der Störsubstanzen; auch fallen Aminosäuren und Amine zusammen an und eine saubere Trennung wird somit erschwert.

Mit der vorliegenden Methode können die Aminosäuren und Amine nach wäßriger Extraktion in DNP-Derivate überführt und ohne weitere Vorreinigung mit organischen Lösungsmitteln extrahiert werden. Die DNPAmine erscheinen im vorliegenden Arbeitsgang getrennt von den Aminosäuren. Bei der Dinitrophenylierung in rein wäßrigem alkalischen Milieu reagieren die Amine nicht mit DNFB. Bei der Dinitrophenylierung der Amine in Wasser-Dioxan-Alkali werden auch Aminosäuren, allerdings nicht quantitativ, dinitrophenyliert. $\mathrm{Da}$ aber im ersten Extraktionsgang die DNP-Amine und überschüssiges Dinitrofluorbenzol sowie Dinitrophenol aus

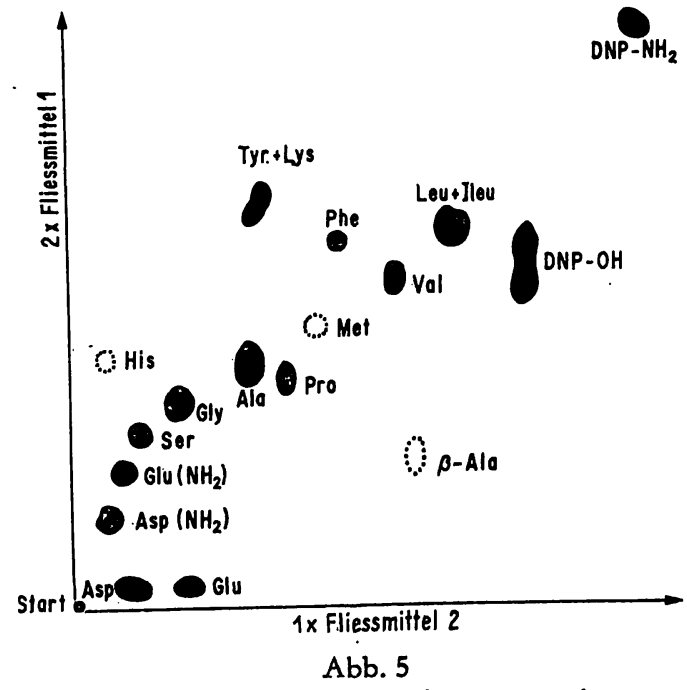

Atherlösliche DNP-Aminosäuren eines Stuhls; punktierte Flecken: nur in Spur vorhanden

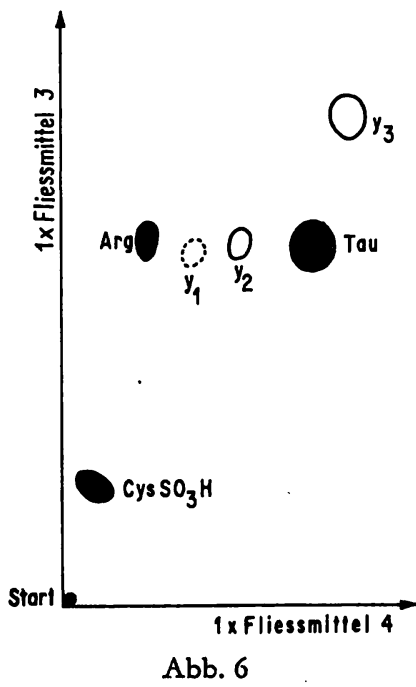

Säurelösliche DNP-Aminosäuren eines Stuhls; punkticrte Flecken: nur in Spur vorhanden; nicht identifizierte Verbindungen: $Y_{1}-Y_{3}$

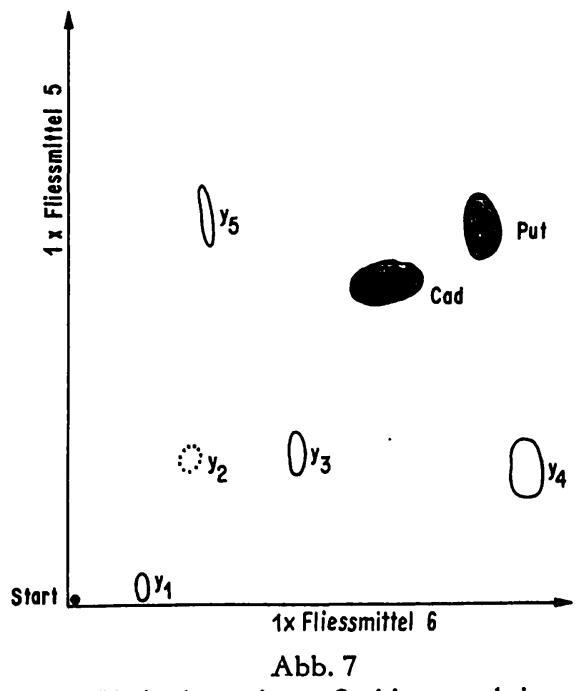

DNP-Amine eines Stuhls; punkticrte Flecken: nur in Spur vorhanden; nicht identifiziertc Verbindungen: $Y_{1}-Y_{5}$ 
der alkalischen Lösung extrahiert werden, verbleiben die Aminosäuren in der wäßrigen alkalischen Phase. Man kann somit die Aminosäuren und die Amine getrennt praktisch in einem Arbeitsgang bestimmen.

Die Methode erscheint zuverlässig und einfach durchführbar. Eigenartigerweise waren die Muster an Aminosäuren und Aminen bei unseren Normalfällen relativ einheitlich. Wir erhielten kein völlig ungleichmäßiges Kontinuum an Aminosäuren und Aminen, das wir wegen der Einwirkung der Darmbakterien eigentlich erwartet hatten. Wir konnten auch keine Peptide nachweisen - jedenfalls nicht in größerer Konzentration. Weitere Untersuchungen sind vor allem in pathologischen Fällen von Durchfall und Malabsorption und bei der Cöliakie notwendig. Auch reicht das untersuchte Material nicht aụs, um gesicherte Normalwerte anzugeben.

\title{
Literatur
}

1. Bickel, H., Mschr. Kinderhk. 112, 173 (1964). - 2. PerheenTUPA, J. und J. K. VISAKorpr, Lancet $I I, 813$ (1965). - 3. HoofT, C., J. Timmermans, J. Snoeck, I. Antener, W. Oyaert und Ch. van den Hende, Ann. paediatr., Basel 205, 73 (1965); ANTENER, I., persönl. Mitteilung. - 4. SPACKMAN, D. H., W. H. Stenn und S. Moore, Analytic. Chem. 30, 1190 (1958). - 5. Cramer, F., Papierchromatographie, Verlag Chemie GmbH., Weinheim/Bergstr. (1962). - 6. Clotten, R. und A. Clotren, Hochspannungselektrophorese, Georg Thieme Verlag, Stuttgart
(1962). - 7. Patakr, G., Dünnschichtchromatographie in der Aminosäure- und Peptid-Chemie, Walter de Gruyter \& Co., Berlin (1966). - 8. Walz, D., A. R. Fahmy, G. Pataki, A. NiederWIESER und M. BRENNER, Experientia, Basel 19, 213 (1963). 9. BürGi, W., J. P. Colombo und R. Richterich, Klin. Wschr. 43, 1202 (1965). - 10. McIntrRe, F. C., L. M. Clements und M. Sproull, Analytic. Chem. 25, 1757 (1953). - 11. PatakI, G., persönl. Mitteilung.
Dr. H.-Ch. Curtius

$\mathrm{CH} 8032$ Zürich, Steinwiesstr. 75

\section{Nachweis und Bestimmung von Phenacetin, N-Acetyl-p-aminophenol sowie ihren Hauptumwandlungsprodukten in Harn und Serum}

\author{
Von H. Büch, K. PFLEger und W. RüDIGER ${ }^{1}$ ) \\ Aus dem Institut für Pharmakologie und Toxikologie (Direktor: Prof. Dr. W. Rummel) und dem Institut \\ fïr Biochemie (Direktor: Prof. Dr. H.-J. Bielig) der Universität des Saarlandes, Homburg/Saar - Saarbriicken
}

(Eingegangen am 18. Juli 1966)

Es werden Methoden zur Bestimmung von Phenacetin, N-Acetyl-p-aminophenol („NAPAP“), NAPAP-sulfat und NAPAP-glucuronid im Harn angegeben. Mit gleicher Methodik können Phenacetin und NAPAP im Serum bestimmt werden. Die Bestimmbarkeitsgrenze für Phenacetin und NAPAP liegt bei $4 \mathrm{mg} \%$ (im Harn) bzw. $1 \mathrm{mg} \%$ (im Serum). Die Nachweisbarkeitsgrenze beträgt für NAPAP mit Folins Phenolreagenz 0,5 $\mu \mathrm{g} /$ Fleck und für Phenacetin im UV-Licht $2 \mu \mathrm{g} /$ Fleck. NAPAP-sulfat und NAPAP-glucuronid können im Harn bis zu einer Konzentration von $20 \mathrm{mg} \%$ bestimmt und bis $2 \mu \mathrm{g} /$ Fleck nachgewiesen werden. Nach Gabe von Phenacetin bzw. von NAPAP an Ratten in Harn und Serum durchgeführte Bestimmungen zeigen, daß sich die Verfahren infolge ihrer einfachen Handhabung für Untersuchungen über den Stoffwechsel dieser beiden Pharmaka eignen.

Methods are given for the determination of penacetin, N-acetyl-p-aminophenol („NAPAP“), NAPAP-sulphate and NAPAP-glucuronide in urine. The same methods can be used for the determination of phenacetin and NAPAP in serum. The limits of measurement are $4 \mathrm{mg} \%$ for phenacetin (in urine), and $1 \mathrm{mg} \%$ for NAPAP (in serum). The limits of detection are $0.5 \mu \mathrm{g} / \mathrm{spot}$ for NAPAP with Folin's phenol reagent, and $2 \mu \mathrm{g} / \mathrm{spot}$ for phenacetin in UV-light. NAPAP-sulphate and NAPAP-glucuronide can be determined in urine down to a concentration of $20 \mathrm{mg} \%$ and detected as low as $2 \mu \mathrm{g} / \mathrm{spot}$. Determinations in the urine and serum of rats after the administration of phenacetin or NAPAP show that these methods, because of their easy operation, are suitable for investigations on the metabolism of these two pharmaccuticals.

Ein einfaches Verfahren, das dem Toxikologen aus einer Harnprobe von etwa $1,0 \mathrm{~m} l$ indirekt den Nachweis und die Bestimmung der häufig verwendeten Analgetica Phenacetin und N-Acetyl-p-aminophenol („NAPAP“c) erlaubt, haben wir kürzlich beschrieben (2). Ermittelt wird dabei p-Aminophenol, das durch salzsaure Hydrolyse aus den im Urin vorliegenden Hauptumwandlungsprodukten der beiden Analgetica entsteht. Mit dieser Methode können dem behandelnden Arzt nicht nur in Vergiftungsfällen sondern auch bei chronischem Abusus ausreichende Angaben über die Ausscheidung im Urin gemacht werden.

Zum näheren Studium des Abbaues und der Ausscheidung dieser Stoffe haben wir nun Verfahren aus-

1) Ein Teil der Ergebnisse wurde auf der 6. Frühjahrstagung der Deutschen Pharmakologischen Gesellschaft, Mainz 1965, vorgetragen (1). gearbeitet, welche es erlauben: 1 . Phenacetin („I") und NAPAP („II") im Serum und im Harn quantitativ zu erfassen und 2. die Hauptumwandlungsprodukte (IIsulfat und II-glucuronid) im Harn zu bestimmen. Mit diesen Verfahren, die im folgenden beschrieben werden, wurden bereits einige Untersuchungen sowohl bei der Ratte als auch beim Menschen durchgeführt (3-6).

Trennung und qualitativer Nachweis Harn -

Die Trennung der zu analysierenden Produkte gelingt mit Hilfe der Dünnschichtchromatographie (DC). Chromatographiert man Harnproben von Ratten, denen 2-4 Stdn. vorher NAPAP (beispielsweise $150 \mathrm{mg} / \mathrm{kg}$ i. p.) verabreicht worden war auf fluoreszierendem Kieselgel mit einem neutralen Fließmittel (Aceton/nButanol/Wasser $=50: 40: 10$ ), so sieht man bei Bè- 